\title{
Por fuera del esencialismo. Dispositivos desidentificadores en Clarice Lispector y Nicola Constantino
}

\author{
Outside of essentialism. Dis-identification devices in \\ Clarice Lispector and Nicola Constantino \\ Por fora do essencialismo. Dispositivos desidentificadores \\ em Clarice Lispector e Nicola Constantino
}

\section{Mariela Herrero}

UNIVERSIDAD NACIONAL DE ROSARIO, ROSARIO/FONDO PARA LA INVESTIGACIÓN CIENTÍFICA Y TECNOLÓGICA (FONCYT), ARGENTINA

Licenciada en Letras. Actualmente se encuentra desarrollando en la

Universidad Nacional de Rosario (UNR), y bajo la dirección del Dr.

Álvaro Fernández Bravo, su tesis de doctorado "Estéticas de la errancia.

Literatura, arte contemporáneo y tecnologías de la proximidad en

los siglos XX y XXI en Latinoamérica", en el marco del Proyecto de

Investigación Científica y Tecnológica (PICT) Ficciones en transición:

representaciones liminales de la literatura y la cultura visual

latinoamericana contemporáneas de la Agencia Nacional de Promoción

Científica y Tecnológica. Se desempeña, además, como auxiliar de investigación en la cátedra de Literatura Argentina I, también en la UNR, donde desarrolla el proyecto Modernización y tecnologías visuales en el siglo XIX. La fotografía como germen de la ficción en la década del ‘80. Correo electrónico: herreromariela@gmail.com

Artículo de reflexión

Documento accesible en línea desde la siguiente dirección: http://revistas.javeriana.edu.co 


\section{Resumen}

El artículo analiza dos objetos estéticos provenientes de diferentes disciplinas artísticas. El objetivo es dar cuenta de cierta expansión o desborde que estos objetos experimentan en la búsqueda y el intento por cuestionar la noción de frontera disciplinar y especificidad del medio, entendido como algo estático y acabado. Se trata de rastrear de qué modo estos gestos, que se enmarcan en el contexto más amplio y complejo del arte contemporáneo latinoamericano, exceden los límites del arte y se exhiben como objetos mutantes, en fluctuación constante, problematizando la categoría de obra y conduciendo a una desidentificación de los soportes y los materiales con que estas son producidas.

Palabras clave: inespecificidad; desidentificación; arte contemporáneo; Clarice Lispector; Constantino

\section{Abstract}

The present article proposes a comparative analysis between two aesthetic objects from different artistic disciplines. The objective is to show a certain expansion that these objects experiment trying to question the disciplinary notion and the specificity of media, understood as something static and concluded. It's about tracking in which way these gestures, framed in the broader context of contemporary and Latin American art, exceed the limits of art itself and are displayed as mutants objects, in constant fluctuation. They problematize the category of "art work" and lead to a dis-identification of the medium and materials with which these are produced.

Keywords: inespecificity; disidentifiers; contemporary art;

Clarice Lispector; Constantino

\section{Resumo}

$\mathrm{O}$ artigo analisa dois objetos estéticos provindos de diferentes disciplinas artísticas. $\mathrm{O}$ objetivo é dar conta de certa expansão ou estouro que estes objetos experimentam na procura e tentativa por questionar a noção de fronteira disciplinar e especificidade do meio, entendido como algo estático e acabado. Trata de rastrejar como é que estes gestos, que se enquadram no contexto mais abrangente e complexo da arte contemporânea latinoamericana, excedem os limites da arte e são exibidos como objetos mutantes, em flutuação constante, problematizando a categoria de obra e conduzindo a uma desidentificação dos suportes e os materiais com que são produzidas.

Palavras-chave: inespecificidade; desidentificação; arte contemporânea; Clarice Lispector; Constantino

RECIBIDO: 2 DE OCTUBRE DE 2015. ACEPTADO: 29 DE NOVIEMBRE DE 2015. DISPONIBLE EN LÍNEA: 1 DE JULIO DE 2016

\section{Cómo citar este artículo:}

Herrero, Mariela. "Por fuera del esencialismo: dispositivos desidentificadores

en Clarice Lispector y Nicola Constantino". Cuadernos de Literatura 20.40

(2016): 103-118. http://dx.doi.org/10.11144/Javeriana.cl20-40.fedd 


\section{Introducción}

Desde hace ya algunas décadas, el arte contemporáneo viene constituyendo una problemática en sí misma. Ya sea por la dificultad que implica periodizarlo (véase Giunta), ya sea por la imposibilidad de definirlo, parecería identificarse siempre con la forma de un interrogante que se extiende en el tiempo y escapa a todas las respuestas posibles.

A pesar de todo, se han intentado rastrear aquellos síntomas comunes que emergen cuando se busca responder a la pregunta ¿qué es el arte contemporáneo? Los parámetros con los que nos encontramos son múltiples; sin embargo, es posible localizar una tendencia que procura conceptualizar estos gestos o expresiones artísticas como "liminares", "en tránsito", "mutantes" y "mudables", "informes", "inespecíficos", que si bien proponen un diálogo - tenue, por cierto - con cierta tradición en la que se inscriben, ${ }^{1}$ lo hacen para polemizar con ella, para cuestionar y vulnerar los modelos y moldes ya conocidos. Obras que escapan o evitan su parentesco o genealogía con tradiciones, escuelas o corrientes estéticas, porque precisamente operan como movimientos que desplazan las fronteras del arte y conducen a una desdesfinición de la obra, incluso a una desidentificación de los soportes o los materiales que se ponen a funcionar en su producción. Un arte que parece anclado en el presente como categoría temporal rectora pero que, sin embargo, se muestra permeable y susceptible de ser atravesado por diversas temporalidades; inasimilables, las manifestaciones artísticas que se llevan a cabo según estos "principios" desclasificadores intervienen, además, como fuerzas deslocalizadoras que buscan proyectarse y expandirse a lo largo y lo ancho de la historización del arte.

Al tiempo que se tensionan categorías como pertenencia y especificidad, ${ }^{2}$ se produce una expansión en términos como identidad, campo, singularidad, diferencia o esencialismo, los cuales adquieren nuevas posibilidades, entre las cuales se observan: la de extender y desdibujar sus contornos y atributos disciplinares, la de incorporar elementos heterogéneos o, también, la de crear regímenes de am-

1 Ticio Escobar advierte en este punto una paradoja. Según Escobar, "nuestro tiempo impugna los fundamentos heredados pero, en cuanto aún no ha podido establecer un soporte propio, vacila si no se apoya en ellos. La contemporaneidad quiere rematar una vieja empresa ilustrada: la de terminar de disolver los núcleos metafísicos que lastran su derrotero (fundamento, totalidad, origen, identidad, etc.); pero no olvida que esos duros meollos significan también los recaudos de su estabilidad, los mojones de sentido que han trazado los rumbos de aquel derrotero" ("Parpadeos", 69-94).

2 Para leer con más detalle la problemática en torno de la pérdida de especificidad y de pertenencia remito al trabajo que realiza Florencia Garramuño en Mundos en común. 
bivalencia entre lo real y lo ficticio como un modo de resistir a una representación homogénea del mundo.

Dispositivos o artefactos que desbordan los sistemas de clasificación porque, para su construcción, los artistas apelan y apuestan por un trabajo de indiferenciación con los materiales y los soportes con que estas obras se componen. Todo ello posibilita pensar en ellos como artefactos multiplicadores de sentidos, pero también de lenguajes, de modos de experimentar - a través de ellos- el espacio, el tiempo, la realidad, el arte en todas sus variantes.

Esta "expansividad" de los medios y soportes que se reconoce en prácticas artísticas contemporáneas tiene sus antecedentes en los gestos vanguardistas que ya proponían e incitaban a la producción de un arte "nuevo" y profanador de las categorías del pasado. No obstante, el arte contemporáneo no puede disociarse hoy de los movimientos de pensamiento y reflexión que recorren la sociedad en su complejidad y sus contradicciones. Siguiendo esta línea nos preguntamos ¿cuál puede ser el sentido del arte en plena época de mundialización y globalización, con todos aquellos cambios tecnológicos, sociales y culturales que este nuevo panorama supone? ¿Qué cuestionamientos y reposicionamientos críticos se producen en esta "sociedad global de la comunicación" en la que tanto la sobresaturación de información como el desborde de la espectacularización provocan una estetización de todo lo que encuentran a su paso?

Como ya lo ha señalado Ticio Escobar, "en cualquier momento histórico, las transformaciones tecnológicas abren nuevas posibilidades para complejizar la experiencia y estimular la sensibilidad. Pero simultáneamente convocan nuevos riesgos de empobrecimiento de la una y estropeo de la otra" (Arte fuera 52). Por ello, este trabajo se propone analizar el problema de la inespecificidad y la no pertenencia en el arte y la literatura latinoamericana en relación con el impacto de las tecnologías de la proximidad. Para ello, centraremos nuestro estudio en el texto Un soplo de vida, de la brasileña Clarice Lispector, y en la videoinstalación Vanity/Tocador, de la argentina Nicola Constantino, ${ }^{3}$ puesto que creemos que ambas obras se encuadran dentro de la lógica de la inespecificidad, fundamentalmente a partir de un diálogo que entablan con este nuevo sensorium que contribuye a desespecificar el estado del arte actual.

3 La obra puede consultarse en la web de la artista plástica: http://nicolacostantino.com.ar/ tocador.php 
En las dos artistas, el desborde, la liminalidad no está señalada exactamente por la presencia de otra disciplina u otros soportes que le son ajenos a la propia, sino que se trata de una mutación dentro del mismo lenguaje. ${ }^{4}$ Constantino continúa trabajando desde soportes visuales y a partir de estos, y en su caso, Lispector hace lo propio con el lenguaje literario. Sin embargo, es notable que en el caso de la brasileña el gesto que opera sobre el lenguaje y la forma tradicional que debería tener la novela parece ser más corrosivo. La extrañeza que la lectura de Un soplo de vida produce $^{5}$ se origina en un disloque de los elementos que componen el relato: la desarticulación de la trama y su reducción en fragmentos aparentemente inconexos abren paso a la presencia de cuadros independientes, sueltos, cápsulas narrativas donde es posible rastrear una historia leve, pero ya no un argumento, una trama que articule lo que se relata. Precisamente, en esa "narración alborotada", como la da en llamar Benedito Nunes, en verdad, clarea la tan buscada libertad formal traducida en el deseo por alcanzar todo aquello que derive en la deconstrucción del sentido y la identidad, lo que puede leerse en el siguiente fragmento:

4 Como señala Florencia Garramuño: "La crisis de la especificidad del medio no ha sido durante estas últimas décadas el único modo en que el arte contemporáneo ha ido definiendo una idea de inespecificidad y de no pertenencia. También al interior de un mismo lenguaje o soporte literario o artístico, el mismo movimiento de cuestionamiento de la pertenencia y de la especificidad encuentra otras maneras de manifestarse. No solo es posible decir que la literatura ha expandido su medio o soporte para incorporar, de un modo creciente, otros lenguajes al interior de su discurso literario - con la incorporación de fotografías, imágenes, blogs, chats y correos electrónicos, por un lado, pero también por otro lado con los puntos de conexión y fuga entre diversos discursos literarios, como las memorias, lo documental, y el ensayo, entre otros. Además, aun cuando los textos no apelen a una indiferenciación tan marcada con respecto a otros órdenes, también en un número cada vez mayor de textos literarios una serie de perforaciones en su interior - el vaciamiento de la categoría de personaje, por ejemplo; la desestructuración de la forma novela, en la ficción; los modos de establecer una cierta continuidad entre poesía y prosa como discursos indiferenciados-, han hecho estallar desde el interior de la literatura la posibilidad de definir tanto a la literatura en general como a los géneros y modalidades discursivas en particular a partir de una especificidad que, aunque en proceso de construcción, tuviera por lo menos un sentido provisorio o al menos limitado al texto en cuestión. No se trata de ese movimiento por el cual cada texto buscaría o definiría para sí una especificidad única, exclusiva y propia, sino precisamente de lo contrario: de que en esos textos nada de lo propio le pertenece al texto, aun encerrado en sus propias fronteras, haciendo evidente que es precisamente la idea de especificidad de lo literario y de la propiedad de lo literario que fundaría una pertenencia lo que parece haber entrado en una crisis intensa. También en las obras plásticas o las instalaciones que reducen los contrastes entre materiales diferentes se presenta, mediante otros dispositivos, este cuestionamiento de lo propio" (Mundos 158 y 159).

5 Vale aclarar que Un soplo de vida es un libro póstumo, publicado en 1978 y que muchas de estas cuestiones ya pueden leerse o detectarse en sus libros anteriores. 
Eu perdi o meu estilo: o que considero um lucro: quanto menos estilo se tiver, mais pura sai a nua palavra. Tenho necessidade, na minha solidão, de confiar em alguém e por isso fiz Ângela nascer: quero manter diálogo com ela. Mas acontece que, em páginas anteriores a estas, em páginas escritas que já rasguei, notei que meu diálogo com Ângela é diálogo de surdos: um diz uma coisa e o outro diz sim mas a coisa diversa, e venho eu dizendo não, e vejo Ângela nem sequer me contradizer. Cada um de nós segue a próprio fio da meada, sem ouvir muito o outro. É a liberdade. (Lispector 6o)

Lispector propone una escritura-devenir mediante la cual cuestiona la certeza del poder referencial de la palabra. Todo su texto vuelve insistentemente sobre la idea de la muerte de la palabra como instrumento referencial incuestionable. La palabra resulta algo insuficiente, escaso; el lenguaje que recorre $U n$ soplo de vida es un lenguaje exangüe, en vías de extinción, tal y como lo conocemos. La palabra no alcanza para traducir el pensamiento; por eso Lispector la extrema, fractura sus sentidos posibles hasta volverla una abstracción, un signo que simboliza otra cosa, impensable, que desborde los códigos de la representación convencional:

O que Angela escreve pode ser lido em voz alta: suas palavras são voluptuosas e dão prazer físico. Eu sou geométrico, Ângela é espiral de finesse. Ela é intuitiva, eu sou lógico. Ela não tem medo de errar no emprego das palavras. E eu não erro. Bem sei que ela é uva sumarenta e eu sou passa. Eu sou equilibrado e sensato. Ela está liberta do equilíbrio que para ela é desnecessário. Eu sou controlado, ela não se reprime- eu sofro mais do que porque estou preso dentro de uma estreita gaiola de forçada higiene mental. Sofro mais porque não digo porque sofro. (Lispector 25 )

No resultaría forzado leer en Lispector un desvío de su producción literaria hacia algo que excede propiamente el campo y que se acerca de un modo notable hacia prácticas del arte contemporáneo más actual. Pero ¿en relación con qué gestos del arte contemporáneo se da esta operación? Reinaldo Laddaga considera que esta tendencia surge en los artistas a partir de cierta inclinación por "construir dispositivos de exhibición de fragmentos de mundo, que se presentan de modo tal que las posiciones de sujeto que se constituyen en la escena que componen difieran de las que el largo siglo XIX les había atribuido a productores y receptores" (14). De esta manera, los lectores, más que leer, asistirían al despliegue continuo de una práctica cuyo rasgo más sobresaliente sería la sensación de errancia, la actualización y la actualidad permanente de un desplazamiento. 
Ahora bien, ¿dónde reside la liminaridad, la inespecificidad en Constantino? Nicola utiliza el soporte del video, explota el documentalismo, la veracidad y la ligazón con el registro de lo real que el video le provee para llevar a un límite esa relación y para hacer visible el mecanismo de artificio. La puesta que Constantino despliega apunta a poner a funcionar el soporte de otra manera a la que está habituado a hacerlo. El registro ilustra la construcción de la obra, cuyo argumento, podría decirse, coincide con el de Lispector en cuanto versa alrededor del problema de la creación. En la misma línea de la brasileña, Constantino crea la figura del artista entre bambalinas, pero lo registra no en una actitud voyeurista, sino como un mecanismo que ayude al espectador a descubrir la textura ficcional de la obra. A darse cuenta de lo obvio, de la artificiosidad y la mentira.

El eje de ambas obras se ubica, podríamos decir, en la problemática de la creación, en la experiencia de la creación y sus efectos. La obra que se crea, que se construye - y cuyo proceso se exhibe como un modo de desnudar el artificio de la representación- parece tener una implicancia directa en la figura de las artistas en cuestión. Las dos tematizan la tensión del artista entre ser el mismo y ser otro. La duplicación, el desdoble, representan el fantasma de una realidad paralela en la que la alteridad y el doble son figuras recurrentes. ${ }^{6}$ Una suerte del mito de Frankenstein en las dos artistas recorre sus obras en torno a la necesidad de dejar de ser ellas mismas y convertirse en otras, en el producto de su creación, en su propia creación. Lispector crea la figura de un AUTOR que, a su vez, necesita inventar un "personaje para conocer a través de su creación", para "tener un fascímile de diálogo". Nicola se exhibe a sí misma en Vanity también en pleno proceso de transformación. El empleo del maquillaje remite a la idea de máscara, de disfraz; sin embargo, los rasgos de identidad nunca se pierden completamente, porque lo que verdaderamente interesa es mostrar el proceso a través del cual el artista pasa de ser algo "corriente" a convertirse en tal gracias a la producción de la obra. Esto también es observable en Lispector que si bien ya había puesto a funcionar esta operación en La hora de la estrella, este coqueteo

6 Estos temas están muy presentes en las dos artistas y son recurrentes en varias de sus obras. Los animales, las flores, la exploración con lo impersonal en Lispector, parecen encontrar cierto punto de contacto con la persistente búsqueda de Constantino en torno a la inquietante relación que se establece entre alteridad e identidad; también en la rosarina son constantes las referencias a animales, clones, máquinas, la mutación en general. En ese sentido, puede leerse una confluencia en la problemática y el cuestionamiento a la esencia, a la noción de especie que, más que pregonar la deshumanización o la desidentificación, estarían proponiendo renovadas y sugerentes maneras de percibir, entender e intervenir en lo heterogéneo, en lo diferente, en lo colectivo, problema vertebral de la época contemporánea. 
con la posibilidad de superponer o confundir rasgos biográficos de la autora con los de sus personajes ya puede detectarse en textos como Agua viva, La pasión según $G H$ o La araña, por mencionar solo algunos. ¿ $\mathrm{C}$ Se trataría, entonces, de una sustitución de la fetichización del autor por la simulación/actuación de una figura desconocida?

\section{2.}

Del texto como performance (entendiéndolo como un evento o acontecimiento único, irrepetible, que tiene lugar en un aquí y ahora puntual) de Clarice Lispector a la videoinstalación de Constantino, la obra se presenta como una fluctuación, un objeto oscilante que parece arrastrar, en su deriva, la figura del autor/creador (véase $\mathrm{Bal}$ ). Pero ¿hacia qué o hacia dónde se orienta esta desmaterialización del objeto estético? Y en esa fuga hacia otra cosa fuera de sí ihacia dónde o hacia qué deriva la figura del autor?

La performance, según Paloma Vidal, se exhibe como un gesto de aproximación del escritor-artista que se arriesga, cuando se expone, al peligro de diluirse, de perder su propio cuerpo en la indefinición de la frontera que separa arte y vida:

Herdeira das vanguardas, um dos traços da performance é questionar os limites da arte e, nesse gesto, aproximá-la da vida. Quando o performer faz do próprio corpo seu material de trabalho, está deliberadamente questionando o distanciamento que funda a idéia de obra e apostando na possibilidade de que ela seja uma experimentação subjetiva e, quem sabe até, com novas formas de subjetividade.

Tanto en el texto de Lispector como en la obra de Constantino, los ecos de la performance están presentes de modo diferente en cada caso; no obstante, en ambas se observa una tensión entre la categoría de autor/creador como una figura que se constituye, se "produce" junto a la obra (casi como si el sentido de la obra fuera, en verdad, la construcción de la autoría), y la presencia constante de ese creador que, así como se muestra, con sus falencias e insuficiencias está interviniendo permanentemente en la producción de sentido y cuestionando la libertad del lector/espectador como cocreador. De esta manera se reformularía la apuesta de lo que Bourriaud entiende como un arte relacional, ${ }^{7}$ esto es, aun cuando la noción de interactividad y la apelación al público sigue siendo clara,

7 Para ampliar la noción de "arte relacional", véase Bourriaud, Estética relacional. 
el lugar del artista como creador continúa funcionando como una potente marca del proceso artístico.

"Un arte que no sea diferente de la vida sino una acción en la vida, sometida al azar, a la improvisación y a la acción no premeditada", escribe Laddaga para señalar que la tendencia contemporánea en esta nueva "cultura de las artes" es la de construir "dispositivos de exhibición", "espectáculos de realidad" donde la figura del autor realiza "pequeñas entregas" o emisiones en lugar de una obra íntegra y concluida. Sin embargo, Nicola parece sugerir que la premeditación es algo inevitable; que la obra es algo que se medita, se prepara, se arregla, algo que no surge de manera espontánea, "natural". Por eso quizás, son constantes las referencias a su propio lugar como artista en el marco del proceso creativo; sin embargo, la figura de Constantino es algo que también se desfigura, se enmascara o se camufla en la experiencia de construcción de la obra. La vanidad de Nicola se reconoce en ese desdoble, pero asimismo refuerza la categoría de creador, de autor, como la pieza fundamental del proceso artístico, sin la cual la obra sencillamente no existe. Nicola hace a Nicola así como Clarice hace al AUTOR, que declara crear de la nada, a ÁNGELA - el producto de la creación - para entablar un diálogo que es, en verdad, un monólogo consigo mismo, un espejo que devuelve algo que parece ser otra cara, pero que al fin de cuentas es la misma. Porque la escritura en Clarice, el proceso creativo, desatomiza al yo, lo desindividualiza para que la obra surja:

Eu sei que este livro não é fácil, mas é fácil apenas para aqueles que acreditam no mistério. Ao escrevê-lo não me conheço, eu me esqueço de mim. Eu que apareço neste livro não sou eu. Não é autobiográfico, vocês não sabem nada de mim. Nunca te disse e nunca te direi quem sou. Eu sou vós mesmos. (10)

El juego fluctúa entre borrar los rasgos autobiográficos, alterarlos, disimularlos y autoimplicarse, ya sea con la firma de autor (Lispector) o ser el propio sujeto de sus imágenes (Constantino) para, de esta forma, reforzar la idea de artificio. No hay improvisación, sino puesta al desnudo del proceso de "armado", de organización de la obra que es, a fin de cuentas, la composición de la figura del autor/ creador. Sujeto y objeto de la representación, las dos artistas se convierten en una suerte de demiurgo que configura mundos donde nada queda librado al azar.

Subyace, en los dos casos, la pregunta por la identidad, la búsqueda de un autoconocimiento: ¿quién soy, en qué me convierto en el momento de la creación? Y en ambas se observa el mismo deseo por la inestabilidad y el movimiento. No permanecer, escapar de la quietud y la fijeza; transformarse, mutar hacia otra cosa, o hacia otro ser. Nicola se ubica frente a un espejo y desde allí se observa a 
sí misma, se revive una y otra vez en el proceso de representación (de sí misma), conversión y desmaterialización. Lispector anhela la desmaterizalización del lenguaje; su ambición radica en alcanzar el caos desde el que surgirá un lenguaje abstracto alejado de la simbolización; ampliar los límites del lenguaje y de la representación ${ }^{8}$ para que en ese espacio inexplorado, inaugural ingrese todo lo que ella busca expresar: el mundo en su vastedad. Dice Silviano Santiago respecto de la escritura de Clarice:

A trama novelesca de Clarice não reflui da, nem conflui para a história literaria escrita em moldes oitocentistas, para a história como entendida naquele contexto. É um rio que inaugura o seu próprio curso. A literatura é literatura -eis a fórmula mais simples e mais enigmática para apreender o sentido da aula inaugural de Clarice [...] A literatura de Clarice, na sua radicalidade inaugural, se alimenta da palavra, é "um mergulho na matéria da palabra", ou seja, ela está na capacidade que tem a palavra de se suceder a uma outra palavra, sem a necessidade de buscar um suporte alheio ao corpo das próprias palavras que se sucedem em espaçamento. (s. p.)

En este sentido, el azar que pregonan sus textos no responde a una actitud fundada en la búsqueda de un sin sentido, sino que, antes bien, funciona como un mecanismo que posibilita intervenir en lo común, ${ }^{9}$ en lo heterogéneo; estrechar el vínculo y la apertura hacia un otro sin necesidad de identificación más que la del fluir de la vida. ${ }^{10}$

8 "El arte contemporáneo pone bajo sospecha las condiciones de la representación de las que parte [...] El arte contemporáneo, a diferencia del modernista, asume sus aporías con entusiasmo. Se detiene en ese momento negativo que impide la clausura y allí trabaja. No considera la oposición entre signo y forma, apariencia y verdad, forma y contenido, como una disyunción esencial que se filtra desde afuera, sino como una tensión insoluble que permanentemente genera tensiones y forcejeos y reposicionamientos variables. El arte contemporáneo es antiformalista, apuesta a la diseminación y se interesa más por lo extra-estético y por los efectos del discurso más que por la coherencia del lenguaje. Privilegia el concepto y la narración en desmedro de los recursos formales [...] La forma no desaparece completamente pero ya no representa el objeto entero" (Escobar, Arte 16-20).

9 Utilizo el término común en el sentido en que lo utiliza Roberto Esposito en Communitas, esto es: "lo común se identifica con su más evidente opuesto: es común lo que une en una única identidad a la propiedad —étnica, territorial, espiritual - de cada uno de sus miembros. Ellos tienen en común lo que les es propio, son propiedad de lo que les es común" (25).

10 Este mecanismo de desidentificación o, mejor dicho, el gesto de destacar la singularidad presentándola como algo común que pertenece a todos, responde a la necesidad de encontrar una singularidad que aparece en la relación constitutiva con el otro. Creo que aquí se cifra una de las principales problemáticas que atañen a lo "contemporáneo", y que Lispector supo anticipar con sus textos de un modo que, ya para su época, resulta novedoso y sobre todo, 


\section{3.}

El de Lispector es un texto que se propone ir más allá de lo narrativo, incluso más allá de lo literario; que busca y espera nutrirse del contacto con lo extraño, con lo desconocido, con otros lenguajes que exceden lo discursivo, de ahí sus referencias a la música, a la pintura, a través de las cuales nos remite a formas de representación alternativas. Y si bien el marco que restringe el desborde completo continúa siendo el literario, resuena, en todo Lispector, una forma de pensar y presentar la obra que sugiere un diálogo con lo interdisciplinar, particularmente con la forma de la instalación.

Entendida como el formato que abarca a todos los formatos, la instalación - a medio camino entre el soporte y el medio- ocupa un lugar preponderante dentro del ámbito del arte contemporáneo, y asimismo representa una opción formal más que interesante para el cuestionamiento de la especificidad, dado que promueve la integración y la convivencia de diversos materiales, soportes y procesos que se proponen para ser recorridos, atravesados e interferidos por los espectadores:La instalación, indefinible por definición (parte del presupuesto de que por su misma estructura desafía todas las fronteras y categorías del arte), ha sido una forma de producir arte y también un comentario sobre el arte y sobre sus límites - una crítica antinormativa y anticanónica que pretende poner en jaque todos los presupuestos del arte y el sistema social que hace posible tal estatuto artístico-. Dispersa por estar conformada con materiales heterogéneos; incapaz de definir un sentido último en tanto este depende del espectador que la recorre; antitotalizadora, incompleta y, por ende, antiautoritaria, la instalación vendría a ser la forma más propicia y adecuada de dar cuenta de la crisis de la modernidad contenida en la crítica posmoderna. (Speranza 274)

Por su parte, Boris Groys comparte esta caracterización fundamentalmente en lo que respecta a la inespecificidad, y agrega que el aspecto más importante, el que la destaca y distingue del resto de las formas y prácticas artísticas que se conocen, radica en que esta "ocupa" un espacio. Dice Groys:

[...] la instalación es material par excellence, ya que es espacial - y estar en el espacio es la definición más general de lo material. La instalación transforma el vacío, el espacio neutral, público en una obra de arte individual, e invita al visitante a experimentar este espacio como el espacio holístico, totalizante de una obra de arte. Todo lo que se incluye en este espacio se convierte en una 
parte de la obra, simplemente porque se dispone dentro de este espacio. La distinción entre objeto artístico y objeto no artístico se hace insignificante. (54)

Un soplo de vida propone un "recorrido", pero no en el sentido tradicional del término; no se trata de un recorrido espacial transitado por el espectador. Sin embargo, podría decirse que la puesta en crisis de lo específico en Lispector se manifiesta en el lazo que entabla con el "lenguaje" de la instalación, y que es a partir de esta ligazón donde su obra se proyecta más próxima hacia el arte contemporáneo que a la literatura en general. Toda la obra de Clarice Lispector se enuncia como la posibilidad de crear una experiencia común; ese es el punto de partida de su escritura: la creación de "la última palabra" que "será la cuarta dimensión", para la que aún no existen registros, ni modos de entenderla, ni de pensarla, ni de articularla.

En este sentido, Lispector anticipa el desprendimiento de técnicas tradicionales en el campo de la literatura, así como un nuevo modo de percibir el arte, opuesto a los valores hasta entonces reconocidos; antecedentes que constituyen una vía para llegar a la instalación como género artístico que integra diferentes técnicas y materiales y, sobre todo, que integra y transforma el espacio. La obra completa de Lispector aspira a este desvío desde sus primeros textos; sin embargo, su estructura se fue radicalizando con los años hasta alcanzar una inestabilidad a través de dos vías fundamentales: 1) la ampliación de los límites de la representación tradicional, a partir de un deslizamiento que va del arte hacia la vida y viceversa, provocando una contaminación entre el registro ficcional y el de la realidad, y una progresiva libertad del lenguaje, ya no como "representación, ni como creación, sino como vida en sî" (Cámara 197), y 2) la problematización y disolución del objeto literario, entendido como tal, al punto de que dicha disolución permite recuperar el ingreso a la literatura de elementos dispersos, heterogéneos, extraartísticos, es decir, permite recuperar la visibilidad general del ambiente o mundo en que la obra se despliega.

Por otro lado, al proyectarse como un texto-instalación, la obra reclama del lector una posición más activa. Ante la obra "común", ya se trate de pintura o literatura, el espectador principal es el artista, y en muchos casos, también es su propio interlocutor - como vimos que sucedía en el caso de Nicola pero también en el de Clarice con el monólogo-diálogo que mantiene con su AUTOR-. La instalación está totalmente orientada hacia el espectador; su presencia es determinante para el sentido de la obra porque aspira a producir una experiencia de realidad, que resultará siempre particular, siempre diferente porque, tal como lo indica Boris Groys, uno de sus principales aspectos reside en su "caducidad": [...] pienso que esta cualidad de evento es central para el problema entero de la instalación [...] una pintura conserva su identidad en el tiempo. Una insta- 
lación no preserva su identidad con el tiempo. Es un evento en el sentido en que puede transformar su identidad. Puede ser desmantelada y reconfigurada. Creo que la mortalidad es un elemento que está presente en mayor grado en las instalaciones que en la pintura. La pintura está más cerca de reclamar su inmortalidad [...] en comparación con la pintura, la instalación produce en mí un efecto fundamentalmente pesimista, pero muy cercano a la mentalidad contemporánea, esto es, a la experiencia directa de la finitud y la solubilidad de todo. (Kabakov y Groys 3 y 4 )

En la ambición de escribir un texto que lo contenga todo, que lo presente todo, la obra de Lispector encuentra un camino alternativo para su literatura; y allí enlaza con los más significativos principios que vehiculiza el dispositivo de la instalación: inorganicidad de la obra, autonomía de los fragmentos que la componen, cuestionamiento a la especificidad de la disciplina y la problematización de la distancia que constituye la base de la ilusión de la representación artística. La insistencia de la autora en declarar que todo el texto ha sido construido con restos, con "destrozos de libro", parece querer indicar que no es más que la suma de elementos diversos, de sobras y desechos "ordenados caprichosamente", o sea, que son la realidad misma. Cada uno de los fragmentos-diálogos que componen Un soplo de vida pregona en cada frase que eso que estamos leyendo no es más que la realidad misma; la vida en su inocencia, con su crudeza y sus desgarros, la vida y no el arte. ${ }^{11}$

\section{4.}

Una de las más singulares características del arte contemporáneo es que ha resignificado la posición del espectador respecto de la obra. El contemplador kantiano que se dejaba estar en la obra y que gozaba de su pura apariencia sin cuestionamientos es desplazado por un nuevo espectador que debe observar y pensar, debe "trabajar con la obra para realizar una lectura artística, para que poco a poco la obra vaya mostrando las respuestas a sus enigmas" (Oliveras 13). Último eslabón de una cadena de sentido, el espectador constituye un engranaje fundamental en la obra de arte contemporánea puesto que, como señala Laddaga, "esta cultura de las artes se organiza en torno a objetos o performances

11 Es precisamente en esta imposibilidad de distinguir entre realidad y signo lo que, tanto para Kabakov como para Groys, resalta como un punto crucial de la técnica de la instalación: "la técnica consiste en asegurarse de que el espectador nunca, en ningún momento, pueda saber si se está enfrentando a una imagen o una cosa; la tensión de la instalación es la tensión de leer los mismos objetos como signos y como cosas" (Kabakov y Groys 9). 
que aspiran a una movilización de la afectividad" del público (38). Los gestos artísticos que se enmarcan dentro de esta lógica de lo impropio o de lo inespecífico permiten también resignificar las categorías de recepción y producción, estableciendo una "proximidad" entre autor-obra-receptor, en contraposición a la noción benjaminiana de "lejanía", propia de la obra aurática.

En Vanity, la videoinstalación de Nicola Constantino, el espejo que refleja la imagen de la artista durante su transformación, no alcanza a reflejar la del espectador. La escena montada, así como el empleo del espejo y el juego con el doble remiten, en gran medida, a Las meninas, de Velázquez. La presencia del espejo despierta ambigüedad y desvirtúa la realidad de la obra; ante esto, el espectador confunde lo que ve y duda si se trata de un cuadro o de un espejo. Además, tanto la acción como la atmósfera que rodean la escena filmada hacen ingresar la representación teatral al soporte del video socavando la especificidad del medio y tornando imprecisa una imagen que podría entenderse no ya como un plano fijo, sino quizás como un cuadro en movimiento.

Tenemos entonces un recurso altamente reforzado en el que la figura del doble, el espejo y el develamiento del artificio se conjugan en esta instalación apresando la presencia del espectador y asignándole un lugar privilegiado y a la vez obligatorio - como sucede según Foucault en el cuadro de Velázquez-. En su análisis, Foucault consideraba que dicha obra estaría tematizando "la representación de la representación clásica y la definición del espacio que ella abre" (15); es precisamente esa apertura que la instalación habilita, la que permite el ingreso del espectador al espacio de la obra provocando una "desterritorialización y una deslocalización - transitoria-" del espacio público que ocupaba antes de formar parte de la obra.

Vanity supone una apropiación y una alteración respecto del cuadro de Velázquez. El soporte del video le permite a Constantino dar cuenta, conservar y archivar la puesta al desnudo del proceso creativo; la elección y la función del soporte responde aquí a la necesidad de eliminar la distancia de la representación cancelando la condición aurática de la obra. "La manifestación irrepetible de la distancia, por más próxima que esté" (Benjamin 15) ya no es tal a partir del develamiento de la ilusión que sostenía a la representación. Sin embargo, esa "trama singular de espacio y de tiempo" - el aquí y el ahora- no es destronada totalmente, sino que se desplaza hacia otra dirección. En la obra de la rosarina, la reproducción del proceso de transformación que recomienza una y otra vez propone una reauratización del objeto, en tanto suplanta la "originalidad", lo desacraliza para instaurar en su lugar una imagen que no cesa de repetirse y replantear el concepto de origen. Así, lo que no cesa de repetirse no permite fundar - mucho menos establecer- el origen. Copia, reproducción, no origen, 
recomienzo atentan contra la condición aurática de la obra, le quitan el aquí y el ahora; la existencia irrepetible se desplaza por la repetición al infinito. No obstante, la autenticidad del gesto artístico se ubica en la posibilidad de otro "aquí y ahora" que el formato de la instalación ofrece al público que la experimenta. Boris Groys, así lo entiende:

En general, la instalación opera como el reverso de la reproducción. La instalación retira una copia precisa de un espacio no marcado, abierto y de circulación anónima y la coloca - aunque sea temporariamente- en un contexto cerrado, fijo y estable, en el contexto de un topológicamente bien definido "aquí y ahora". (63)

De esta forma, cada vez que la instalación sea desmontada perderá su contexto único y original, y, al mismo tiempo, lo recobrará en cada reedición, en cada nuevo montaje. Cada nuevo comienzo y emplazamiento de la obra la transformará en un objeto distinto, en una "copia de sí misma que experimentará el tiempo y, otra vez, su propia 'iluminación profana' que la convertirá en un original". Precisamente porque la instalación opera como un dispositivo efímero pero, al mismo tiempo, como un evento multiplicador de sentidos que por su tendencia a la finitud, a la caducidad, se presenta más propenso a perder auras viejas y ganar nuevas. En tal sentido, "es, quizás, la misma copia pero se transforma en diferentes originales" (Groys 65).

A pesar de la distancia, no solo física sino temporal, las obras de Lispector y Constantino poseen la potencia de lo contemporáneo; se despliegan y proyectan —en todos los sentidos-,y sobrevuelan el tiempo y las interpretaciones porque gozan de la propiedad de lo incesante y de lo que no puede ser concluido. Lejos del esencialismo proponen una relación indefinible con su época - por lo sucesivamente cambiante-, que se articula sobre los vestigios de todos aquellos paradigmas estéticos que componen la historia del arte. Cuestionan, discuten y deponen la lógica de un campo diferenciado y autónomo en pos de gestos más fértiles y prolíficos que desencadenen el discurrir y la expansión disciplinar, así como el trabajo y la experimentación con materiales heterogéneos, inestables, incluso, por qué no, inasimilables.

Se trataría, por lo tanto, de un arte No nuevo, pero que se nutre del "entre", de la mediación con otras disciplinas, de la mezcla heterogénea o impura donde encuentra "un punto de inquietud y suspenso entre las artes". Un arte que no le teme a la degeneración - puesto que puede transformarse en una vía para su regeneración - porque, en todo caso, tampoco le interesa la defensa de las especificidades; desea la alteridad (por lo menos ilusoria) que prometen esos lenguajes (Speranza 359). 


\section{Obras citadas}

Bal, Mike. "Memory Acts: Performing Subjectivity". Boijmans

Bulletin 1.2 (2001). Web 2 de julio de 2014. Impreso.

Benjamin, Walter. La obra de arte en la época de su reproductibilidad

técnica. Buenos Aires: El Cuenco de Plata, 2011. Impreso.

Bourriaud, Nicolás. Estética relacional. Buenos Aires: Adriana Hidalgo, 2008. Impreso.

Cámara, Mario. "Los secretos movimientos del respirar: palabra, cosa y mundo en Un soplo de vida". Un soplo de vida, de Clarice

Lispector. Buenos Aires: Corregidor, 2011. Impreso.

Constantino, Nicola. Vanity (video-instalación). 2011. Web.

Escobar, Ticio. El arte fuera de sí. Valencia: Institut

Valencia d'Art Modern, 2009. Impreso.

Escobar, Ticio. "Los parpadeos del aura". Cuadernos de Arte 13 (2007): 69-94. Impreso.

Espósito, Roberto. Communitas. Buenos Aires: Amorrortu, 2003. Impreso.

Foucault, Michel. Las palabras y las cosas: una arqueología de las ciencias humanas. Buenos Aires: Siglo XXI, 1968. Impreso.

Garramuño, Florencia. Frutos estranhos. Río de Janeiro: Rocco, 2014. Impreso.

Garramuño, Florencia. Mundos en común. Buenos Aires:

Fondo de Cultura Económica, 2015. Impreso.

Giunta, Andrea. ¿Cuándo empieza el arte contemporáneo? Buenos

Aires: Fundación ArteBA, 2014. Web. 3 de julio de 2014.

Giunta, Andrea. "Parte IV: arte contemporáneo". Escribir las

imágenes. Buenos Aires: Siglo XXI, 2011. 258-277. Impreso.

Groys, Boris. "Políticas de la instalación". Volverse público.

Buenos Aires: Caja Negra, 2014. Impreso.

Kabakov, Ilia y Boris Groys. "De las instalaciones: un diálogo entre Ilya

Kabakov y Boris Groys", Otoño 1990. Web. 7 de agosto de 2014.

Laddaga, Reinaldo. Espectáculos de realidad. Rosario: Beatriz Viterbo, 2007. Impreso.

Lispector, Clarice. Um sopro de vida. Río de Janeiro: Rocco, 1999. Impreso.

Oliveras, Elena, ed. Cuestiones de arte contemporáneo.

Buenos Aires: Emecé, 2008. Impreso.

Santiago, Silviano. "A aula inaugural de Clarice". Folha da Manhã

(7 de diciembre de 1997). Web. 2 de junio de 2014.

Speranza, Graciela. Fuera de campo. Buenos Aires: Anagrama, 2006. Impreso.

Vidal, Paloma. "Performance e homoafetividade em dois romances de João

Gilberto Noll". Revista e-misférica 4.1 (2007). Web. 4 de octubre de 2013. 